Western North American Naturalist 77(2), (C) 2017, pp. 275-279

\title{
ERRATUM: "SPECIES RICHNESS, DIVERSITY, AND ECOLOGY OF CHIRONOMIDAE (DIPTERA) IN FOUNTAIN CREEK: A COLORADO FRONT RANGE SANDY-BOTTOM WATERSHED” (2016)
}

The publisher would like to draw attention to an error in the following print article:

Herrmann, S.J., J.E. Sublette, L.K. Helland, D.R. Nimmo, J.S. Carsella, L.M. Herrmann-Hoesing, AND B.D. Vanden Heuvel. 2016. Species richness, diversity, and ecology of Chironomidae (Diptera) in Fountain Creek: a Colorado Front Range sandy-bottom watershed. Western North American Naturalist $76: 186-252$.

The 14 study site abbreviations were omitted from the column headings of Table 4 (pages 195-198), wherein presence-absence data for chironomid species were given. The headings are given here in order: MC-1, MC-2, MC-3, MC-4, MC-5, UF-1, UF-2, UF-3, UF-4, LF-1, LF-2, LF-3, LF-4, LF-5.

$\mathrm{MC}=$ Monument Creek, $\mathrm{UF}=$ Upper Fountain [Creek], LF $=$ Lower Fountain [Creek]. See Fig. 1 for a map of study sites.

The entire corrected table is reproduced on the following 4 pages. The electronic version archived at scholarsarchive.byu.edu/wnan/ vol76/iss2/5 has been corrected. 


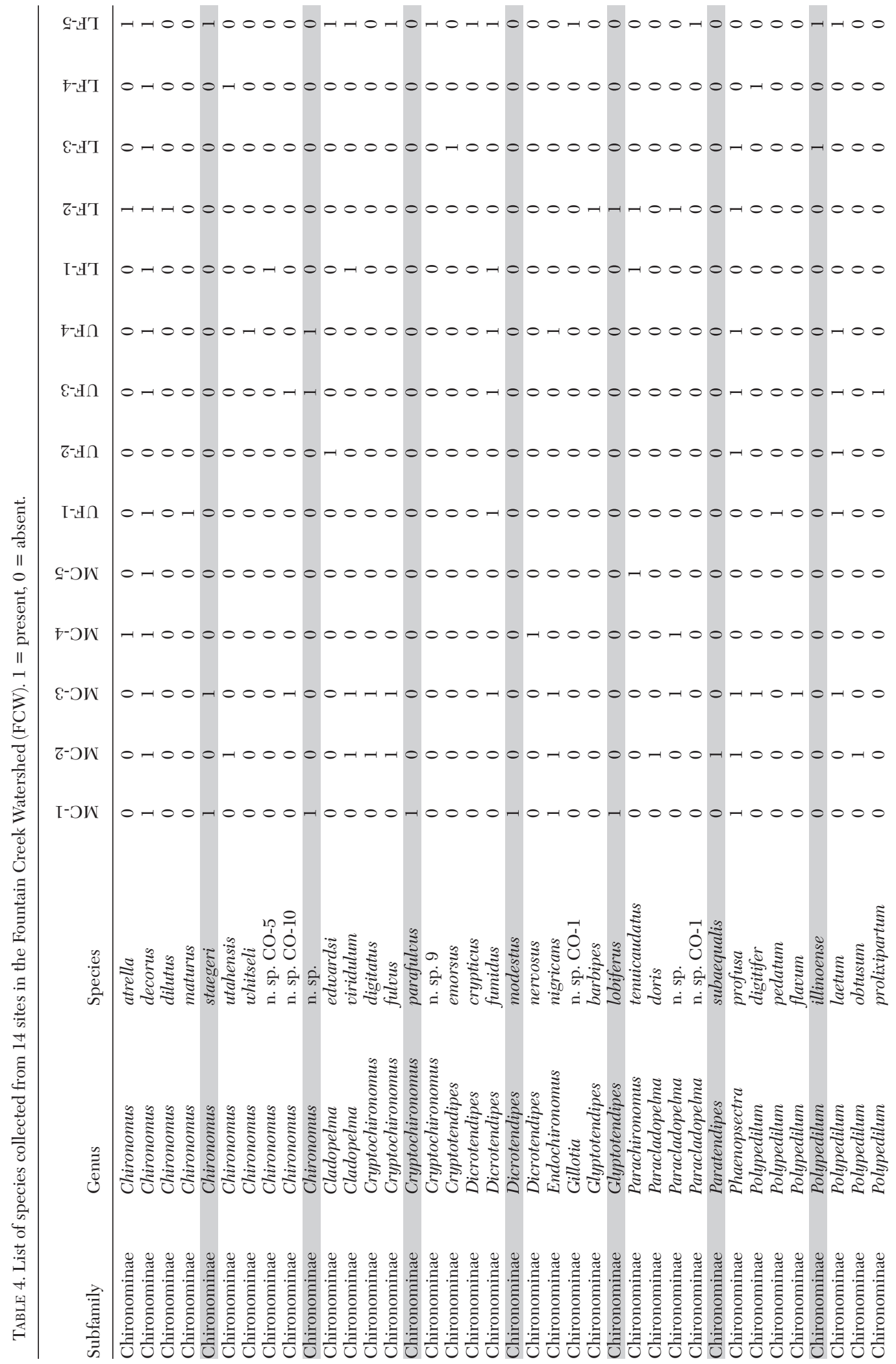




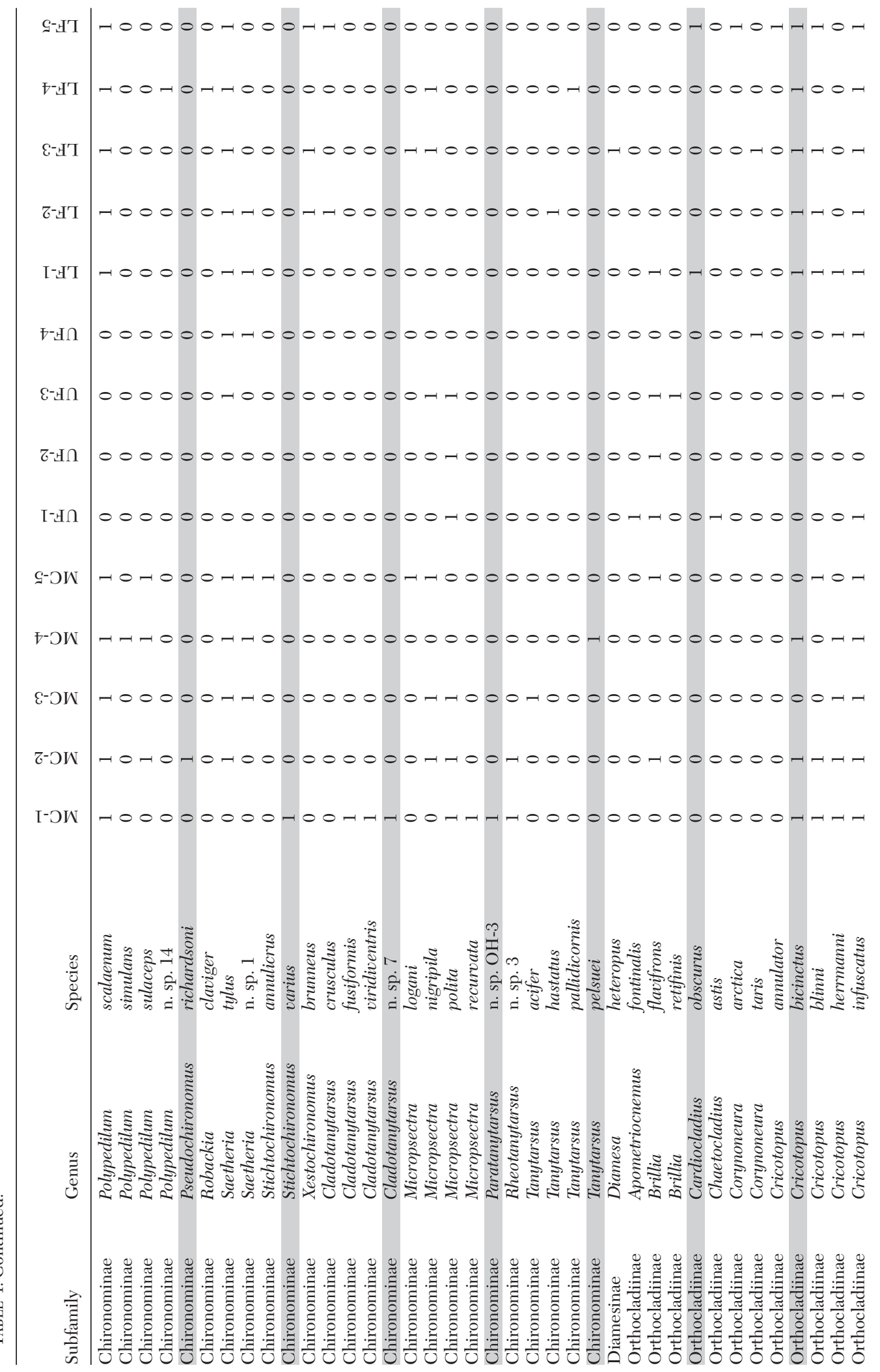




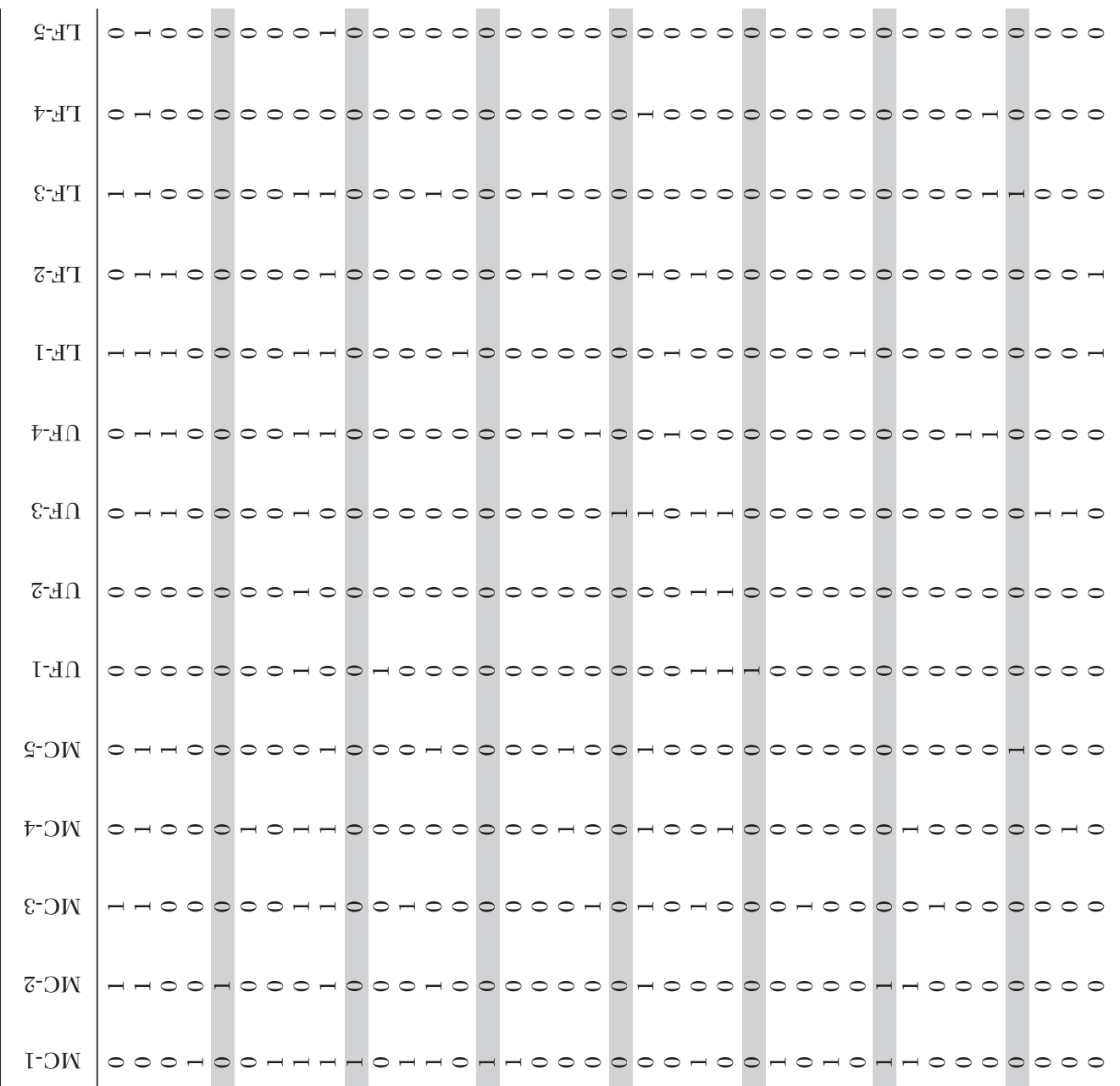

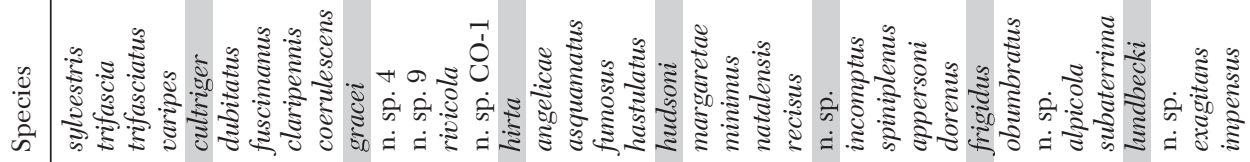

ฐิ

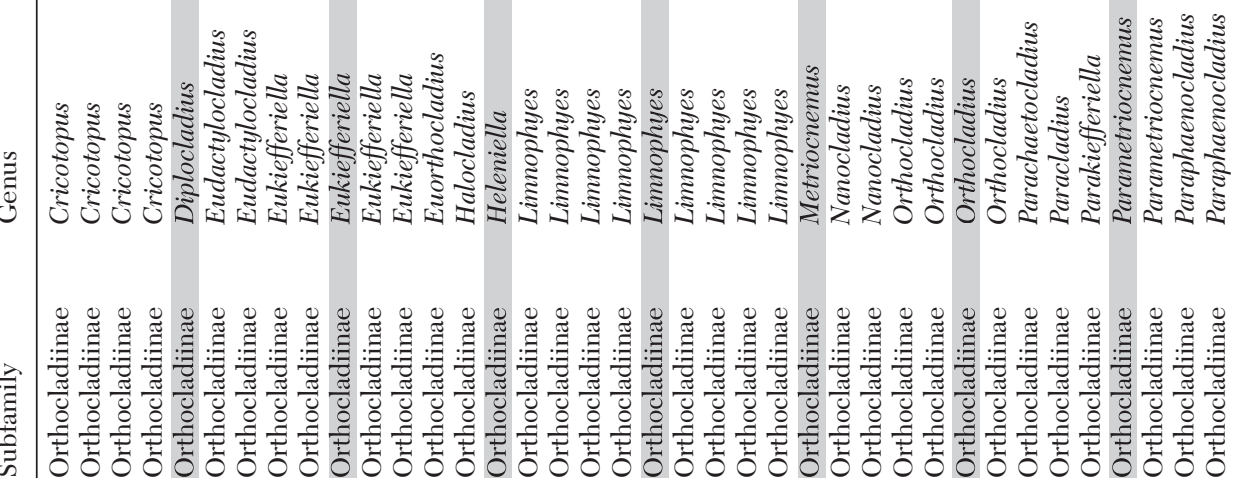




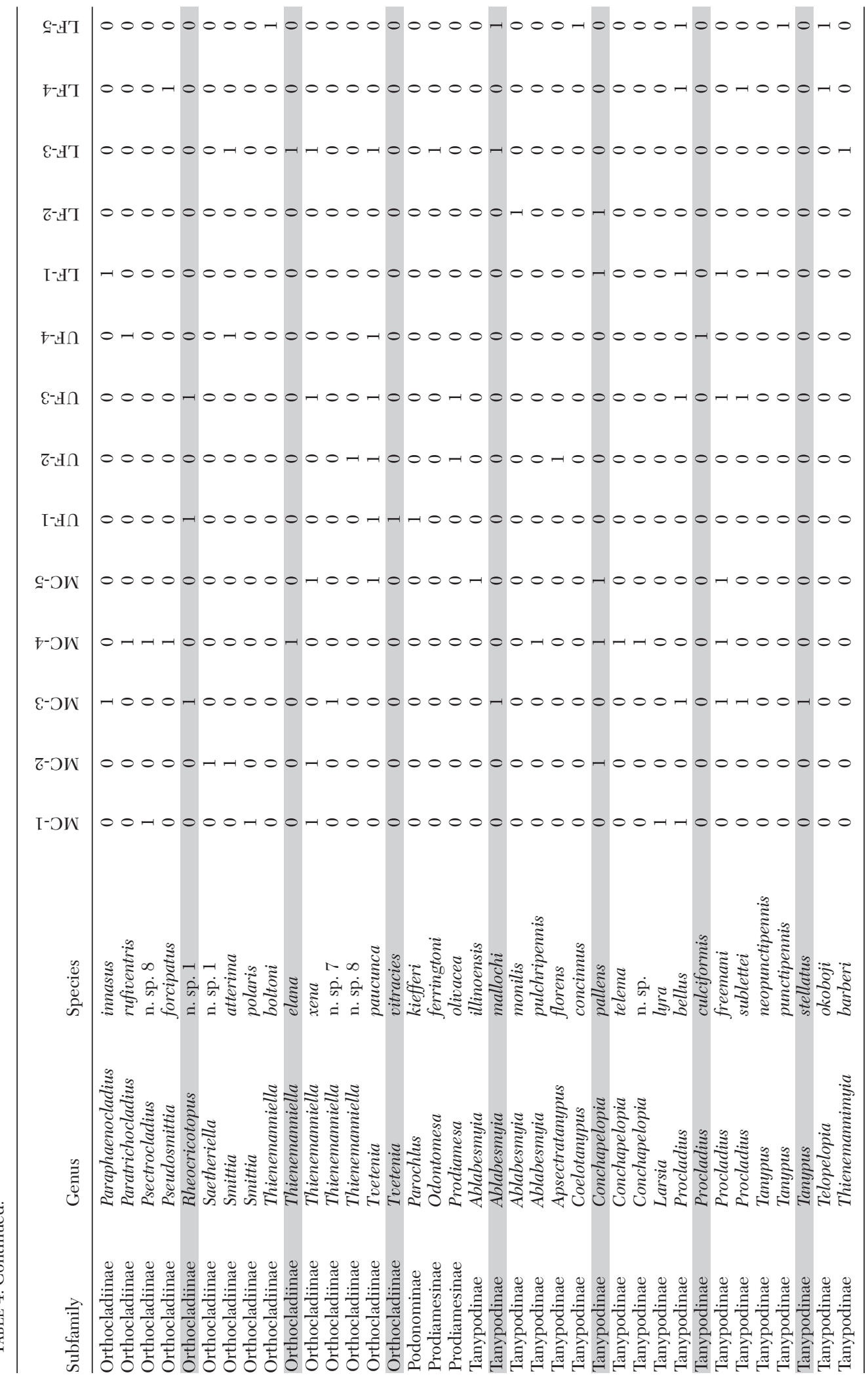

